\title{
AS TENSÕES EUROCÊNTRICAS NO PENSAMENTO DE MARIÁTEGUI E OS DILEMAS DA CONSTITUIÇÃO DO MARXISMO NA AMÉRICA LATINA ${ }^{1}$
}

\author{
Vinicius Limaverde Forte ${ }^{2}$
}

\begin{abstract}
Resumo: Este artigo apresenta as tensões eurocêntricas da interpretação marxista de Mariátegui acerca da formação da sociedade peruana. Por tensões eurocêntricas entende-se o processo de simultânea crítica e reiteração do paradigma eurocêntrico. Por um lado, Mariátegui contribuiria para a crítica ao eurocentrismo a partir de duas vias. Primeiramente, ao apontar como a relação entre capitalismo e colonialismo suscitou a articulação entre diferentes formas de propriedade privada em função da acumulação capitalista, recusando uma pretensa validade universal das etapas de desenvolvimento histórico europeu para compreensão da realidade latino-americana. Em segundo lugar, também contribuiu a partir da proposição da centralidade do papel das populações indígenas no processo de construção de um socialismo indo-americano. Por outro lado, a reiteração do eurocentrismo esteve relacionada com a hierarquia cultural estabelecida entre europeus e não europeus em sua compreensão das relações raciais na América Latina, destacadamente no que concerne das pessoas de origem africana e asiática.
\end{abstract}

Palavras-Chave: Mariátegui. Marxismo. América Latina.

\begin{abstract}
This article presents the findings of Matiátegui on the Eurocentric tensions in his Marxist interpretation regarding the formation of the Peruvian society. Eurocentric tensions is the process of simultaneous criticism and reiteration of the eurocentric paradigm. On the one hand, Mariátegui would contribute for criticizing eurocentrism from two ways. First of all, in pointing how the relationship between capitalism and colonialism has prompted an articulation of different forms of private property aiming capitalist accumulation, refusing an alleged universal validity of the stages of European historical development to understanding the Latin American reality. Secondly, he also contributed from the proposition of the centrality of the role of indigenous peoples in the process of building Indo-American socialism. On the other hand, the eurocentrism reiteration has been related to cultural hierarchy established between European and non-European in their understanding of race relations in Latin America, by far, and particularly for people of African and Asian origin.
\end{abstract}

Keywords: Mariátegui. Marxism. Latin America.

\footnotetext{
1 As questões abordadas neste texto foram originalmente tratadas no quarto capítulo de minha tese (FORTE, 2016), em parte aqui reproduzido.

${ }^{2}$ Professor do Curso de Ciências Sociais da Universidade Estadual Vale do Acaraú (UVA-CE). Mestre em Sociologia pela Universidade Federal do Ceará e Doutor em Sociologia pela Universidade Federal de Pernambuco. Correio eletrônico: viniciuslforte@yahoo.com.br
} 


\section{Mariátegui e a questão do eurocentrismo no marxismo latino-americano}

Neste trabalho objetiva-se analisar as tensões eurocêntricas da interpretação marxista de José Carlos Mariátegui (1894-1930) acerca da formação da sociedade peruana. Consagrado como precursor da nacionalização do marxismo na América Latina (Ricupero, 2000), recorrentemente ressalta-se como característica do pensamento do Amauta ${ }^{3}$ sua abordagem original (Löwy, 1999; Tible, 2009). Destacadamente, esses apontamentos decorrem do contraste em relação às bases eurocêntricas em que certa variante do marxismo foi transposta para o contexto latino-americano, sobretudo sob a hegemonia da III Internacional Comunista (Komintern). Embora referenciado pela importância atribuída à cultura incaica na luta para a criação de um socialismo indo-americano, o que se configura em um patente esforço de provincialização do paradigma eurocêntrico (Chakrabarty, 2000), o pensamento de Mariátegui também é permeado por elementos que reiteram eurocentrismo.

Argumenta-se neste trabalho que isso seria perceptível no que concerne à combinação entre evolucionismo cultural e materialismo histórico no âmbito de suas considerações acerca do debate racial na América Latina. Dessa maneira, ao mesmo tempo em que seria possível apreender um traço romântico e antipositivista no seu pensamento (Löwy, 1999), também haveria certa reiteração de uma perspectiva eurocêntrica, destacadamente mediante sua apropriação da visão evolucionista de Bukharin a respeito das diferenças materiais entre os povos europeus e não europeus. A partir da concepção de Raymond Williams (1979) acerca do processo hegemônico, denomina-se de "tensão eurocêntrica" esse processo de simultânea crítica e reiteração da perspectiva eurocêntrica. Para compreender como crítica e reiteração combinam-se no pensamento de Mariátegui, inicialmente apresenta-se como o eurocentrismo e sua crítica permeiam o marxismo na América Latina.

A penetração do marxismo observou-se de maneira mais considerável na América Latina apenas no início do século XX e tinha uma forte concorrência com as correntes anarquistas no movimento operário, sobretudo até a Revolução Russa. Contudo, mesmo com as limitações de acesso a livros para o estudo das ideias marxistas ${ }^{4}$, estava no horizonte dos

\footnotetext{
${ }^{3}$ Conforme Leila Escorsim (2006), o termo Amauta designa na cultura incaica um homem sábio. Mariátegui o utilizou para nomear uma revista literária peruana que dirigiu entre 1926 e 1930. Após sua morte o marxista peruano passou a ser definido com esse epíteto (Escorsim, 2006).

${ }^{4}$ Edgard Carone (1986) informa que no Brasil até meados da década de 1940 a atividade editorial era significativamente restrita, destacadamente em virtude da intensa censura sofrida pelos livros relacionados ao comunismo, conforme será discutido no próximo tópico.
} 
pioneiros latino-americanos a tentativa de adequar o materialismo histórico às especificidades locais. Referindo-se às experiências revolucionárias de inspiração marxista no continente, Pablo Gonzalez Casanova observa que "el proceso revolucionario en nuestros países no se da sin mediaciones, sino con una gran cantidad de mediaciones, y es en el estudio de estas mediaciones como se va a enrequecer mucho la teoría del proceso revolucionario" (Casanova, 1988, p. 16). Na opinião de Casanova, essas mediações corresponderiam justamente aos esforços de adequar o marxismo às especificidades locais, propiciando a unidade entre conhecimento teórico, realidade empírica e prática revolucionária.

Por sua vez, Michel Löwy chama a atenção para as consequências decorrentes de uma concepção não comprometida com a construção dessa unidade, destacadamente mediante a simples transposição de ideias europeias para a realidade latino-americana. Reside nessa questão o cerne do debate a respeito da relação entre cópia e originalidade das ideias no contexto do marxismo latino-americano. O decalque puro e simples de ideias teria sido prejudicial para o marxismo na América Latina:

\begin{abstract}
Foi o eurocentrismo, mais do que qualquer outra tendência, que devastou o marxismo latino-americano. Com esse termo queremos nos referir a uma teoria que se limita a transplantar mecanicamente para a América Latina os modelos de desenvolvimento socioeconômico que explicam a evolução histórica da Europa ao longo do século XIX. Para cada aspecto da realidade europeia estudado por Marx e Engels [...] procurou-se laboriosamente o equivalente latino-americano [...] Usando esse método, a estrutura agrária do continente foi classificada como feudal, a burguesia local considerada como progressista, ou mesmo revolucionária, o campesinato definido como hostil ao socialismo coletivista etc. Nessa problemática, toda especificidade da América Latina foi implícita ou explicitamente negada, e o continente concebido como uma espécie de Europa tropical, com seu desenvolvimento retardado de um século, e sob o domínio do império norte-americano (Löwy, 2012, p. 10-11).
\end{abstract}

Para Löwy, a chave para compreender a dinâmica da apropriação eurocêntrica do marxismo na América Latina relaciona-se com o domínio hegemônico das diretrizes stalinistas disseminadas pela Komintern, cuja ascensão remete à passagem entre as décadas de 1920 e 1930. Após a Revolução Russa de 1917, houve uma intensificação na disseminação de partidos comunistas nacionais ao redor do mundo, que paulatinamente passaram a integrar uma rede fortemente internacionalizada (Pons, 2014). Durante o período compreendido entre

\footnotetext{
${ }^{5}$ Em livre tradução: "o processo revolucionário em nossos países não se dá sem mediações, mas com uma grande quantidade de mediações, e é no estudo destas mediações que se irá enriquecer muito a teoria do processo revolucionário".
} 
o final da década de 1920 e início da década de 1960, os partidos comunistas hegemonizaram de maneira mais intensa o marxismo latino-americano. Ao longo daqueles anos as diretrizes stalinistas foram hegemonicamente dominantes. Apenas com a Revolução Cubana houve um ponto de inflexão que suscitou uma mudança no paradigma revolucionário latino-americano, na medida em que se fortaleceram perspectivas que não estavam alinhadas ao programa eurocêntrico amparada nas diretrizes da Komintern (Casanova, 1988; Löwy, 2012).

Mas, afinal, como se caracterizaria a matriz eurocêntrica do marxismo na América Latina? Löwy (2012) aponta que o predomínio do stalinismo foi fundamental para tornar hegemônica a reprodução de posicionamentos eurocêntricos junto aos marxistas. Esse processo deu-se, sobretudo a partir da década de 1930, quando passou a haver uma centralização programática e doutrinária ainda mais intensa. O principal traço eurocêntrico da perspectiva dominante junto aos partidos comunistas estava expresso pelo modelo democrático-burguês (Mantega, 1984), concebido como um desdobramento das teses apresentadas por Lenin em As Duas Táticas da Socialdemocracia, elaboradas por ocasião da derrota da Revolução Russa de 1905. O modelo democrático-burguês procura imputar uma perspectiva analítica e um programa político tomando por referência uma concepção etapista da História como via para o socialismo em países de origem colonial, cuja questão agrária não foi resolvida com base na chamada "via clássica", em um processo de acumulação primitiva análogo ao ocorrido na Inglaterra ${ }^{6}$. Por um lado, a não resolução da questão agrária estaria relacionada com a manutenção de resquícios feudais que deveriam ser eliminados para que o capitalismo viesse a consolidar-se plenamente; por outro, a persistência desses traços coloniais seria funcional aos interesses imperialistas, na medida em que se beneficiariam da importação de produtos primários e do enfraquecimento da burguesia nacional.

Em decorrência dessa interpretação da realidade latino-americana, os partidos comunistas nacionais propunham como programa político uma frente única composta por proletários, trabalhadores rurais, setores progressistas da burguesia nacional supostamente prejudicados pelo Imperialismo, podendo-se também abranger outros setores identificados conjunturalmente como progressistas. Como a burguesia nacional estaria debilitada em virtude da aliança entre latifundiários e Imperialismo, impossibilitando o desenvolvimento

\footnotetext{
${ }^{6}$ Denomina-se de "via clássica" para o capitalismo o processo de acumulação primitiva de capital ocorrido na Inglaterra, tomado como exemplar por Marx (2008[1967]). Em síntese: "A chamada acumulação primitiva é apenas o processo histórico que dissocia o trabalhador dos meios de produção" (MARX, 2008[1867], p. 828), caracterizado pela dissolução da servidão feudal e da pequena propriedade camponesa em favor da urbanização e formação da força de trabalho a ser empregada na indústria.
} 
pleno das forças produtivas, os proletários deveriam comandar essa frente única com vistas a cumprir as tarefas da revolução democrático-burguesa. Contudo, mesmo após a obtenção desse objetivo, a classe trabalhadora deveria permanecer mobilizada para gradualmente avançar nas suas reivindicações. A intenção disso era propiciar por uma via pacífica e democrática a aceleração das contradições entre forças produtivas e relações de produção, criando-se as condições para o advento do socialismo. Como resultado da transposição dessa perspectiva para o contexto latino-americano, o modelo democrático-burguês reproduz a ideia de um desenvolvimento sequencial, linear e pretensamente universal, na medida em que considera as etapas do desenvolvimento histórico europeu como a única via de desenvolvimento possível.

\section{Heterodoxia e tensões eurocêntricas no marxismo latino-americano.}

Não obstante o domínio dessa perspectiva entre as décadas de 1930 e 1960, durante esse período também se observou o aparecimento de vertentes críticas ao eurocentrismo no marxismo latino-americano. No entanto, a maior parte dessas abordagens originou-se fora dos partidos comunistas nacionais, partindo de acadêmicos e de militantes trotskistas, como foram os casos de C.L.R. James, Sergio Bagú e Marcelo Segall, por exemplo. Particularmente nos casos de James (2010[1938]) e Bagú (1949) destaca-se a importância atribuída ao debate da questão racial no contexto latino-americano, em uma abordagem marxista que prezava pela compreensão da articulação entre colonialismo e capitalismo, contribuindo para a construção de um ponto de vista a partir do Sul sobre a modernidade. Uma importante exceção dentre os quadros dos partidos comunistas nacionais pode ser observada na trajetória de Caio Prado Jr. O marxista brasileiro integrou o PCB desde o início da década de 1930 até seu falecimento em 1990. Sua interpretação marxista da realidade foi pautada pela busca da especificidade da formação do Brasil, em detrimento da busca de correspondências entre conceitos oriundos de explicações sobre o desenvolvimento histórico da Europa e a realidade brasileira.

Diante desse panorama, pode-se mais facilmente apreender a primazia de Mariátegui no marxismo latino-americano. Conforme Casanova (1988) e Löwy (2012), antes da consolidação da ascendência da Komintern houve espaço para o surgimento de perspectivas mais originais e preocupadas com as especificidades do continente, como foram os casos de Julio Antonio Mella, em Cuba, Ricardo Paredes, no Equador, e José Carlos Mariátegui, no 
Peru. Antes da década de 1930, a contribuição crítica mais relevante no marxismo latinoamericano contra o eurocentrismo veio da produção heterodoxa de Mariátegui, um dos fundadores do Partido Socialista Peruano.

O Amauta possibilitou apreender a articulação entre elementos característicos de diferentes modos de produção no contexto do período colonial peruano, indicando que esse processo transcorria em prol da acumulação capitalista no plano mundial. Com isso, Mariátegui teria uma postura diferente daquela que viria ser disseminada a partir da hegemonia da Komintern. Assim, tem-se na perspectiva do marxista peruano uma recusa da simples transposição automática de conceitos, evitando o estabelecimento inadequado de correspondências imediatas entre categorias analíticas forjadas para compreensão da formação de países europeus e a realidade latino-americana. Outro aspecto original no pensamento de Mariátegui, diz respeito ao seu entendimento acerca do processo revolucionário no contexto peruano. Ao compreender a centralidade da questão agrária para a persistência da dependência do Peru, Mariátegui atentou para o protagonismo dos povos indígenas na luta pelo socialismo. O seguimento da população de ascendência indígena sofria de maneira mais intensa com a exploração imposta pelos senhores de terra. Todavia, a sobrevivência parcial da tradicional forma comunal de propriedade da terra dos indígenas andinos, o ayllu incaico, propiciaria um ponto de partida para a construção de um socialismo indo-americano.

Em ambos os casos tem-se importantes contribuições para uma perspectiva antieurocêntrica no marxismo latino-americano. Não obstante o contraste em relação às versões do marxismo pautadas pelas diretrizes da Komintern, é possível observar a presença de elementos eurocêntricos no pensamento de Mariátegui, sobretudo no que concerne ao debate da questão racial. Conforme observa Juan E. de Castro (2010), ao abordar essa dimensão da produção intelectual do marxista peruano não está em pauta perfilhá-lo junto aos adeptos do determinismo racial, contra quem dirigiu críticas importantes. Ao invés disso, trata-se de considerar os aspectos em que uma visão evolucionista contribui para que Mariátegui formule uma compreensão equivocada, corroborando preconceitos raciais contra as populações de origem africana e asiática no Peru. Antes de analisar a presença de elementos eurocêntricos e antieurocêntricos no pensamento do Amauta, segue-se um debate conceitual acerca da noção de tensões eurocêntricas.

Partindo-se da leitura de Raymond Williams (1979) sobre a concepção gramsciana de hegemonia, concebida como direção político-cultural, considera-se o paradigma eurocêntrico 
uma formação hegemonicamente dominante, tendo como expressões articuladas o universalismo europeu (Wallerstein, 2007) e a colonialidade do poder/saber (Lander, 2000; Quijano, 2010). Para Williams, o processo hegemônico incorpora e supera as noções de cultura e ideologia. Com isso, seu entendimento acerca dos processos hegemônicos remete à ideia que a dominação é vivenciada no âmbito da cultura, concebida como força produtiva constituída e constituidora do modo de vida ordinariamente partilhado. O caráter dinâmico do processo hegemônico é apreendido por Williams mediante as noções de tradições, instituições e formações, cuja expressão histórica pode ser caracterizada como residual, dominante ou emergente. O que se denomina aqui de "tensão eurocêntrica" consiste em uma expressão do processo hegemônico em que uma forma emergente de contestação do eurocentrismo estaria imbuída de alguns elementos dominantes caracteristicamente eurocêntricos. Consequentemente, resultaria daí críticas parciais, onde inadvertidamente seriam incorporados argumentos que reforçariam o eurocentrismo.

Desse modo, a combinação entre evolucionismo cultural e materialismo histórico presente em algumas formulações de Mariátegui, seguindo diretrizes presentes na obra de Bukharin, consistiria em um caso de incorporação do aparecimento de perspectivas emergentes pelo paradigma eurocêntrico hegemonicamente dominante. Ou seja, como Williams concebe o processo hegemônico como dinâmico e relacional, nem mesmo as perspectivas oposicionistas estariam completamente livres da influência do hegemonicamente dominante, podendo sofrer o risco de uma maior ou menor incorporação em conformidade com o grau de subordinação das práticas culturais dos seus respectivos grupos emergentes ${ }^{7}$.

Diante dessas ponderações, cujo intuito era situar o pensamento de Mariátegui no contexto do marxismo na América Latina, ressaltando-se os dilemas decorrentes das suas tensões eurocêntricas, a seguir cabe debater de maneira um pouco mais detida os aspectos de crítica e de reiteração do eurocentrismo presentes nas contribuições do Amauta.

\footnotetext{
${ }^{7}$ Um processo análogo pode ser apreendido na interpretação do Brasil de Caio Prado Jr. Ao mesmo tempo em que o marxista paulista fornece subsídios para a crítica ao eurocentrismo - provincializarando as pretensões universalistas do modelo democrático-burguês e desprovincializando o sentido da colonização brasileira, em vista de sua articulação com a formação do capitalismo como sistema mundial -, há uma reiteração do eurocentrismo mediante a reprodução da hierarquia cultural entre europeus e não europeus em seu debate sobre a questão racial no contexto brasileiro (Forte, 2016).
} 


\section{Mariátegui, a nacionalização do marxismo no Peru e o socialismo indo-americano}

Mariátegui formulou uma crítica marxista orientada para a especificidade da história peruana. Dessa maneira, ele procurou empreender uma apropriação crítica do legado de Marx, em movimento denominado por Ricupero (2000) de "nacionalização do marxismo". Essa apropriação do marxismo em termos nacionais não deve ser concebida de forma a desconsiderar o caráter internacionalista que perpassa o marxismo. $\mathrm{Na}$ verdade, a discussão entre nacionalismo e internacionalismo oferece uma porta de entrada para compreender o pensamento mariateguiano. Apesar da internacionalização hegemônica que vigorou na primeira metade do século XX, transcorrida por meio da Komintern, Mariátegui dissocia a internacionalização do marxismo da sua completa uniformização, procurando conciliá-la com as especificidades nacionais.

Como Mariátegui aderiu ao marxismo para orientar seu entendimento acerca das alternativas emancipatórias para a situação nacional peruana, alguns de seus opositores o qualificaram como adepto de "estrangeirismos". Às críticas de "europeizado" decorrentes de sua postura, Mariátegui retrucava alegando que "não há salvação para a Indo-América sem a ciência e o pensamento europeus ou ocidentais. Sarmiento, que ainda é um dos criadores da argentinidade, foi considerado, na sua época, um europeizado. Não achou melhor maneira de ser argentino" (Mariátegui, 2010[1928], p. 32). Portanto, Mariátegui acreditava na criação de uma alternativa para a sociedade peruana que comungasse a tradição indo-americana e a cultura europeia. As implicações dessa concepção para seu programa político são significativas, constituindo a base de sua defesa de um socialismo indo-americano, concebido articuladamente com o processo histórico internacional:

O socialismo não é, certamente, uma doutrina indo-americana. Porém nenhuma doutrina, nenhum sistema contemporâneo o é nem pode sê-lo. E o socialismo, ainda que tenha nascido na Europa, como o capitalismo, não é tampouco específico nem particularmente europeu. É um movimento mundial, ao qual não se subtrai nenhum dos países que se movem dentro da órbita da civilização ocidental. Esta civilização conduz, com forças e meios de que nenhuma civilização dispôs, à universalidade. A Indo-América, nesta ordem mundial, pode e deve ter individualidade e estilo; porém não uma cultura nem um destino particulares (Mariátegui, 2012[1928], p. 109).

Dessa maneira, a nacionalização do marxismo de Mariátegui constitui-se com base em uma tensão entre o particular e o universal, considerando a individualidade e estilo próprios 
da Indo-América no plano do movimento mundial de disputa entre capitalismo e socialismo. Ao mesmo tempo em que reconhece a origem europeia do socialismo, que logo se internacionalizou, Mariátegui atenta que “[o] socialismo [...] está na tradição americana. A mais avançada organização comunista primitiva que a história registra é inca" (Mariátegui, 2012[1928], p. 109). Por conseguinte, afirma que: "Não queremos, certamente, que o socialismo seja na América decalque e cópia. Deve ser criação heroica. Temos que dar a vida, como nossa própria realidade, em nossa própria linguagem, ao socialismo indo-americano" (Mariátegui, 2012[1928], p. 109). Para tanto, Mariátegui propõe que a tradição socialista incaica seja tomada como ponto de partida para a organização de cooperativas de produção e de consumo como alternativa ao latifúndio feudal, forma de propriedade da terra predominante no Peru. Essa proposição aponta para a busca por um caminho próprio de luta, em conformidade com as especificidades nacionais, sem incorrer em soluções pautadas na cópia de modelos estrangeiros. Mariátegui argumenta que a tradição comunitária incaica forneceria a aptidão moral e material para o fomento de cooperativas de produção e consumo:

Las "comunidades" que han demostrado bajo la opresión más dura condiciones de resistencia y persistencia realmente asombrosas, representan en el Perú un factor natural de socialización de la tierra. El indio tiene arraigados hábitos de cooperación. [...] La "comunidad" puede transformarse en cooperativa, con mínimo esfuerzo ${ }^{8}$ (Mariátegui, Pesce, 2010[1929], p. 79).

Enquanto o cooperativismo na Europa relaciona-se com os vínculos comunitários estabelecidos entre os trabalhadores a partir dos sindicatos, no Peru esses vínculos já estariam consolidados nas serras, ao passo que, nas cidades, o proletariado peruano ainda precisaria desenvolvê-lo. Conforme aponta Löwy (2012; 2013), essa proposta de Mariátegui possui paralelo com o debate estabelecido entre Vera Ivanovna Zasulitch (2013[1881]), partidária dos “populistas russos”, e Karl Marx (2013[1881]). Nas cartas trocadas entre ambos, discutiuse acerca da possibilidade de uma transição ao socialismo sem conceber o capitalismo como pré-requisito. Segundo essa tese, deveria partir-se da experiência do mir russo para a construção do socialismo. Dessa forma, Marx e Engels (2013[1882]) afirmam que "a atual

\footnotetext{
${ }^{8}$ Em livre tradução: “As 'comunidades' que têm demostrado sob a opressão mais dura condições de resistência e persistência realmente assombrosas, representam no Peru um fator natural de socialização da terra. O índio tem arraigados hábitos de cooperação. [...] A 'comunidade' pode transformar-se em cooperativa, com mínimo esforço".
} 
propriedade comum da terra na Rússia poderá servir de ponto de partida para uma evolução comunista" (Marx, Engels, 2013[1882], p. 125).

Com base em Anderson (2010) e Lindner (2010), pode-se indicar que esse posicionamento representa uma significativa modificação na própria postura de Marx e Engels quanto às suas concepções acerca do desenvolvimento histórico e à transição para o socialismo. Assim, no lugar da reiteração eurocêntrica do progresso, haveria nessa discussão uma tensão em torno dessa ideia. O caráter teleológico do socialismo abandonaria uma perspectiva unilinear e adotaria a multilinearidade, sem necessariamente romper por completo com o progresso, apesar da significativa contribuição para esse intento. Assim como ocorre por parte de Marx e Engels, há no pensamento de Mariátegui uma ruptura com a linearidade estabelecida pela sucessão cumulativa entre diferentes estágios e desenvolvimento. Evita-se dessa maneira um dos traços característicos da ideia de progresso.

A tensão entre a especificidade nacional e a perspectiva internacionalista, presente na concepção mariateguiana do marxismo como programa político socialista, também é observável em sua análise histórica. Mariátegui atribui importância crucial à questão da terra na formação da sociedade peruana. Sua intenção é compreender como se forjou no Peru um arranjo que articulava diferentes formas de propriedade da terra e de organização do trabalho, onde internamente a hegemonia cabia ao latifúndio feudal, cuja orientação, porém, era definida no plano internacional em função das demandas capitalistas.

Mariátegui inicia procurando demonstrar como o colonizador espanhol forjou relações de produção feudais, englobando a propriedade comunal da terra característica dos incas: "Por cima das ruínas de uma economia socialista, [os colonizadores] lançaram as bases de uma economia feudal" (Mariátegui, 2010[1928], p. 34). Assim, apesar do predomínio feudal, o problema agrário no Peru também tem como componente "a sobrevivência da comunidade e de elementos de socialismo prático na agricultura e vida indígena” (Mariátegui, 2010[1928], p. 69). A desnaturação da propriedade coletiva da terra forçava um vínculo de dependência dos indígenas para com os latifundiários, por isso a "comunidade sobrevivia, mas dentro de um regime de servidão" (Mariátegui, 2010[1928], p. 81). A esse vínculo entre latifúndio e propriedade comunitária da terra, Mariátegui acrescenta que: "como para o trabalho das fazendas da costa se recorreu à importação de escravos negros, foram misturados, aos elementos característicos de uma sociedade feudal, elementos e características de uma sociedade escravista" (Mariátegui, 2010[1928], p. 35). Juntamente a essas atividades, na 
colônia ainda havia a mineração voltada para exportação, desenvolvida na região dos altiplanos andinos.

Assim, deve-se observar que o fato de Mariátegui referir-se à existência de feudalismo no Peru durante o Período Colonial não implica necessariamente em um ponto de vista eurocêntrico. O Amauta deteve-se na configuração particular da sociedade peruana para definir sua situação como feudal, não havendo nisso uma transposição apriorística do conceito de feudalismo, como ocorreu em muitos casos inspirados nas diretrizes da Komintern. Por isso, ao conceber o feudalismo no Peru, Mariátegui indicou tanto seu entrelaçamento com o escravismo e com a propriedade comunal da terra dos indígenas no plano local, quanto sua articulação com o sistema capitalista no plano internacional. Sem atentar para essa articulação, não seria possível caracterizar adequadamente o feudalismo peruano, conforme a visão de Mariátegui.

Portanto, nesse caso, o feudalismo não consistiria em uma etapa prévia ao capitalismo. Como observa Grosfogel: "Mariátegui acreditava que o latifúndio feudal e as relações capitalistas faziam parte de um único sistema capitalista internacional” (Grosfogel, 2013, p. 34). Dessa forma, seria possível entrever na interpretação de Mariátegui a interdependência entre feudalismo, propriedade coletiva da terra e escravismo em vista da acumulação de capital no plano mundial.

Se por um lado há uma patente crítica ao eurocentrismo no que concerne à teoria da revolução e à análise da formação econômica e social peruana, por outro lado no plano da cultura há aspectos problemáticos nas formulações de Mariátegui. Jean Tible (2009) atenta para o caráter limitado do conhecimento de Mariátegui sobre a cultura andina e de sua agricultura. Aponta, inclusive, certa idealização da organização política e social incaica, bem como insuficiência em suas ponderações a respeito da propriedade e da organização do trabalho agrícola nos Andes. Além do ayllu, a exploração da terra também abrangeriam partes dedicadas ao Estado e ao Sol. Essas lacunas decorreriam dos seus limitados encontros com ativistas indígenas em Lima, sendo a ausência de um conhecimento empírico mais profundo das condições de vida nas serras um dos limites em seu pensamento acerca das populações indígenas peruanas (Tible, 2009). Além disso, outro importante limite no pensamento de Mariátegui se expressa no modo como foi compreendida a questão racial na América Latina. 


\title{
4 Os limites eurocêntricos de Mariátegui
}

Além de caracterizar a estrutura econômica peruana, Mariátegui (2010[1928]) também refletiu sobre as bases de legitimação do domínio dos gamonales sobre os indígenas, afirmando que seu fundamento se assentava no discurso racial. Inicialmente, esse expediente era utilizado pelos europeus que reivindicavam para si uma superioridade inata em relação aos índios. Posteriormente, esse argumento teria sido retomado pelos latifundiários criollos, propondo como solução para a situação do indígena sua assimilação pela miscigenação com a "raça" branca:

\begin{abstract}
A suposição de que o problema indígena é um problema étnico se nutre do repertório mais envelhecido das ideias imperialistas. O conceito de raças inferiores serviu ao Ocidente branco para sua obra de expansão e conquista. Esperar a emancipação indígena de um cruzamento ativo da raça aborígene com imigrantes brancos é de uma ingenuidade antissociológica, concebível apenas na mente rudimentar de um importador de carneiros merinos. [...] A degeneração do índio peruano é uma invenção vagabunda dos leguleios feudalistas (Mariátegui, 2010[1928], p. 57).
\end{abstract}

Como alternativa ao determinismo racial, Mariátegui defende que "[a] mestiçagem precisa ser analisada não como questão étnica, e sim como questão sociológica" (Mariátegui, 2010[1928], p. 323-324). Com isso, o marxista peruano propõe atentar para os aspectos econômicos e sociais vinculados à hibridação entre diferentes tipos sociais que resultaria no mestiço como um novo tipo social. No entanto, sua perspectiva sociológica limita-se à refutação de parâmetros raciais para definição da superioridade europeia, na medida em que corrobora sua redefinição em termos culturais por meio do evolucionismo:

O preconceito das raças diminuiu, mas a noção das diferenças e desigualdades na evolução dos povos se ampliou e enriqueceu em virtude dos progressos da sociologia e da história. A inferioridade das raças de cor já não é um dos dogmas dos quais se alimenta o maltratado orgulho branco. Mas todo relativismo de hoje não é o suficiente para abolir a inferioridade da cultura (Mariátegui, 2010[1928], p. 323).

Assim, em vez de a "raça" servir de critério para a delimitação da superioridade europeia, as condições culturais, sociais, econômicas e técnicas convertem-se em parâmetros a serem adotados para a consideração do progresso civilizacional. Em função de sua crítica ao 
determinismo racial incorrer em uma visão evolucionista, instaura-se uma aporia no argumento de Mariátegui contrário à subjugação com base na noção de raça. Sua discordância para com o determinismo racial dá-se a partir do materialismo histórico, que também é mobilizado para explicar as diferenças entre as "raças" em termos sócio-históricos. Conforme é explicitado no documento escrito em coautoria com Hugo Pesce, as ideias apresentadas por Bukharin em A Teoria do Materialismo Histórico (1921) oferecem importante subsídio para a maneira como é formulada essa questão em termos marxistas.

Mariátegui e Pesce (2010[1929]) transcreveram e endossaram uma longa passagem do texto de Bukharin que, sinteticamente, apresenta as seguintes teses: 1) As teorias raciais não estariam em conformidade com os fatos, pois apregoam a existência de características imutáveis às diferentes "raças", mas não se observa essa fixidez de atributos ao longo da história, na medida em que as diferentes "raças" apresentam significativas variações em suas configurações sociais ao longo do tempo, sendo a supremacia branca europeia um fato relativamente recente; 2) Não seria possível afirmar que um negro médio teria qualidades análogas a um europeu médio, pois existiriam diferenças entre seus níveis culturais em decorrência do estado das forças produtivas vigente no período histórico considerado na comparação. Disso segue-se que o caráter estático e naturalista das teorias raciais é substituído por uma visão materialista e evolucionista da História que concebe a cultura como consequência do estado das forças produtivas (Mariátegui, Pesce, 2010[1929]). Então, passa a vigorar uma compreensão amparada na noção de hierarquia cultural, originada pelas desigualdades de condições das forças produtivas e pelas relações de exploração de classe. Dessa forma, Mariátegui argumenta que os indivíduos de qualquer "raça" estariam aptos a se apropriarem da cultura europeia, bastando que as condições materiais necessárias sejam oferecidas.

Assim, embora antipositivista, Mariátegui faz concessão a uma concepção evolucionista do materialismo histórico ao realizar sua crítica às doutrinas raciais. Com isso, seria possível identificar na sua obra a convivência entre aspectos que corroboram e que contrariam a noção de "diferença global" (Connell, 2007). Em decorrência disso, as ideias de Mariátegui estariam perpassadas de elementos eurocêntricos em algumas ocasiões, apesar da sua tônica predominantemente antieurocêntrica. Como expressão da tensão decorrente da combinação entre formações dominantes (evolucionismo) e emergentes (paradigma decolonial), tem-se uma relevante ambiguidade na reflexão mariáteguiana sobre a questão 
racial. Dessa forma, embora tenha procurado fundamentar um posicionamento contrário ao racismo, Mariátegui adota uma visão do materialismo histórico que o reproduz.

Portanto, a crítica mariateguiana ao eurocentrismo constituinte das teorias do determinismo racial não rompe por inteiro com pressupostos eurocêntricos devido a sua adesão ao materialismo histórico evolucionista de Bukharin, que considera os brancos europeus culturalmente superiores aos negros africanos em virtude de sua sociedade encontrar-se em condições materialmente mais evoluídas. A conjugação entre evolucionismo e materialismo histórico, imbuídos pela ideia de progresso, fez com que Mariátegui incorresse em uma visão hierárquica das diferentes civilizações, embora não incorresse em essencializações, na medida em que admitia a possibilidade de evolução para um estágio material mais elevado. As consequências desses pressupostos teóricos adotados por Mariátegui são expressas nas suas considerações a respeito da composição étnica do povo peruano. Assim, muito embora sua intenção tenha sido criticar o argumento da supremacia branca, ressaltando o cunho imperialista subjacente ao discurso de hierarquização racial em bases cientificistas, ao se pautar pela combinação entre evolucionismo cultural e materialismo histórico, o Amauta refere-se de maneira depreciativa aos africanos escravizados:

A contribuição do negro, vindo como escravo, quase como mercadoria, aparece ainda mais nula e negativa. O negro trouxe sua sensualidade, sua superstição, seu primitivismo. Não estava em condições de contribuir para a criação de uma cultura, mas sim, em vez disso, prejudica-la com a influência crua e vivente de sua barbárie (Mariátegui, 2010[1928], p. 323).

No entanto, sua crítica não se estenderia aos indígenas devido às condições materiais e culturais que caracterizavam sua sociedade antes da invasão dos colonizadores hispânicos. Assim, o Amauta observa na tradição socialista incaica, combinada ao industrialismo europeu, a possibilidade de construção de uma modernidade alternativa para o Peru, a exemplo das sociedades orientais:

A sociedade indígena pode se mostrar mais ou menos primitiva ou atrasada, mas é um tipo orgânico de sociedade e de cultura. As experiências dos povos do Oriente, o Japão, a Turquia e a própria China, já provaram como uma sociedade autóctone, mesmo depois de um longo colapso, pode encontrar por seus próprios passos, e em muito pouco tempo, o caminho da civilização moderna e traduzir para o seu próprio idioma as lições dos povos do Ocidente (Mariátegui, 2010[1928], p. 326). 
É importante frisar que, não obstante tenha imputado a condição de inferioridade material e cultural às populações não europeias, o intento de Mariátegui era emancipatório, diferentemente do pleito defendido pelos gamonales. Ou seja, apesar de ter mobilizado uma perspectiva que serve para justificar a supremacia racial branca, não era sua intenção promover sua reiteração, embora o tenha feito. Nesse sentido, tem-se no caso de Mariátegui a expressão de um impasse característico do marxismo, sobretudo na primeira metade do século $\mathrm{XX}$, que diz respeito às suas dificuldades com a questão da interseccionalidade. Particularmente no que se refere à questão da população negra, o Amauta indica a importância de sua inserção na indústria e nos sindicatos, corroborando um posicionamento corrente junto à Komintern que estimulava a organização sindical dos trabalhadores negros, ainda que em organizações específicas nos países que não permitissem seu ingresso nas mesmas agremiações que os brancos. Todavia, sua ideia a respeito da inserção dos negros no meio industrial urbano e no movimento sindical parte da noção de que houve uma atitude passiva por parte dos africanos introduzidos no Peru como escravos durante o Período Colonial, bem como que teria sido desenvolvida uma "domesticidade" associada às suas atividades artesanais e domésticas: "La industria, la fábrica, el sindicato, redimen al negro de esta domesticidad. Borrando entre los proletarios la frontera de la raza, la conciencia de clase eleva moral, históricamente, al negro. El sindicato significa la ruptura definitiva de los hábitos serviles que mantienen" 9 (Mariátegui, Pesce, 2010[1929], p. 67). Note-se que, como alternativa para "redimir o negro", Mariátegui indica a supressão das diferenças raciais em favor de uma homogeneização pautada pelo desenvolvimento da consciência de classe dos trabalhadores.

Em suma, apesar de Mariátegui demonstrar a importância do debate racial para a compreensão da formação da sociedade peruana, destoando das perspectivas marxistas eurocêntricas que desconsideram os fatores extra econômicos, sua abordagem é marcada por um acento evolucionista. Por um lado, o paradigma eurocêntrico é descentrado no que concerne à análise da base material, mas, por outro lado, careceria de maior elaboração nos aspectos vinculados à reflexão sobre a cultura, "raça" e gênero. Sua valorização da cultura andina é acompanhada na mesma medida pela desvalorização da cultura dos povos africanos submetidos ao trabalho escravo no Peru. Com isso, Mariátegui alude ao "sensualismo" e ao

\footnotetext{
${ }^{9}$ Em livre tradução: "A indústria, a fábrica, o sindicato, redimem o negro desta domesticidade. Apagando entre os proletários a fronteira da raça, a consciência de classe eleva moral, historicamente, o negro. O sindicato significa a ruptura definitiva dos hábitos servis que mantém".
} 
"primitivismo" da população negra que, por sua "barbárie", seria um fator de corrupção cultural, reproduzindo alguns dos motes mobilizados mais recorrentemente para sua inferiorização. A partir dessas considerações sobre a interpretação do Amauta sobre a realidade peruana, pode-se perceber que o problema do eurocentrismo no marxismo latinoamericano não se restringiu exclusivamente ao modelo democrático-burguês, mas também se manifestou no debate sobre a questão racial e no seu papel na luta de classes.

\section{Considerações Finais}

A reflexão sobre a relação entre a dominação pautada na posse dos meios de produção e aquela decorrente de fatores culturais foi bastante prejudicada no marxismo pela hegemonia do cientificismo soviético durante a primeira metade do século XX. Como observa Casanova (2006), embora Lenin tenha fornecido subsídios teóricos importantes para se pensar a questão do "direito de autodeterminação" dos povos no interior das nações componentes da União Soviética para assegurar o direito das minorias étnicas, com a ascensão do stalinismo, os debates sobre autodeterminação, etnicidade e a questão nacional passaram a ser tratados como particularismo de cunho separatista e nacionalista. Institucionalizou-se dessa maneira o argumento reproduzido incansavelmente nos partidos comunistas ao redor do mundo sobre a primazia da luta de classes em relação às demandas étnicas e de gênero, argumentando-se que a resolução das contradições derivadas da base material resolveria os demais conflitos. Ainda de acordo com Casanova, a postura assumida pela URSS de retirar da pauta o debate sobre a questão étnica implicou na imposição de barreiras epistemológicas para se pensar questões vinculadas às especificidades locais em detrimento do debate considerado mais geral sobre Imperialismo e luta de classes. Isso ocasionou uma problematização fragmentária no pensamento marxista sobre a questão racial (Casanova, 2006).

Porém, a despeito dessa tendência, as especificidades da América Latina contribuíram para a contestação dessa perspectiva eurocêntrica. Destarte, deve-se notar ainda que Mariátegui não foi o único marxista a propor a articulação entre a luta de classes e a questão racial no marxismo latino-americano. Essa tendência também é observada de maneira mais aprimorada nos trabalhos de Sergio Bagú sobre o capitalismo colonial, nas reflexões de C. L. R. James sobre a revolução de São Domingo, atual Haiti, e na problematização de Pablo Gonzalez Casanova sobre o colonialismo interno. Todavia, dentre os intelectuais 
mencionados, apenas C. L. R. James preocupou-se em ressaltar o protagonismo da população negra na luta de classes.

Seria possível afirmar que, por um lado, na interpretação pioneira de Mariátegui seria manifesta uma estrutura de sentimento indianista no marxismo latino-americano ${ }^{10}$. No entanto, ainda assim o marxista peruano não obteve êxito em descentrar inteiramente uma visão eurocêntrica acerca dos negros e dos asiáticos. Da mesma forma não atentou para a discussão a respeito da questão de gênero nas relações de dominação colonial. Isso é bastante sintomático do caráter interseccional da colonialidade do poder, o que suscita a presença de tensões eurocêntricas na medida em que se empreende uma abordagem parcial do paradigma eurocêntrico, tornando possível a combinação entre sua crítica e sua reiteração na análise histórica e nas lutas políticas.

Portanto, ao mesmo tempo em que o pensamento do Amauta apresenta contribuições para o descentramento do paradigma eurocêntrico, também detém elementos que o corrobora. Por um lado, Mariátegui aponta para a articulação entre diferentes formas de propriedade dos meios de produção e organização do trabalho no âmbito da relação entre capitalismo e colonialismo. A quebra desse padrão de poder estabelecido com a colonização é definida a partir do protagonismo das populações indígenas no processo revolucionário. Mediante a retomada de aspectos identificados como caracteristicamente socialistas, haveria um traço cultural que contribuiria para o estabelecimento de relações de produção pautadas na propriedade coletiva dos meios de produção e em uma organização pautada no associativismo. Essas dimensões do pensamento de Mariátegui estariam em plena consonância com uma visão não eurocêntrica no bojo do marxismo, destoando de maneira significativa das diretrizes de inspiração stalinista da Komintern. Por outro lado, seu entendimento a respeito das hierarquias culturais entre europeus e não europeus no que se refere às relações raciais no contexto latino-americano expressam uma patente limitação eurocêntrica. Resulta dessa crítica parcial uma tensão eurocêntrica no pensamento do marxista peruano, também presente em outros marxistas heterodoxos, como foi o caso de Caio Prado Jr. Com efeito, torna-se perceptível que os dilemas decorrentes da hegemonia do paradigma

\footnotetext{
${ }^{10}$ A noção de "estrutura de sentimentos" foi cunhada por Williams (1979). Conforme o marxista galês, o termo refere-se a uma espécie de "emergência preliminar" vivenciada, mas ainda não inteiramente articulada. Expressa uma experiência nova ainda não inteiramente apreendida de maneira plenamente sistemática. As estruturas de sentimentos consistem em experiências sociais cujo processo está em curso, por isso ainda não se sedimentaram de modo a fixarem-se como ocorre com as formações ou as instituições. Mas mesmo sendo caracterizadas por um processo em curso, essas experiências sociais ainda assim são estruturadas. As estruturas de sentimentos seriam como as soluções ou misturas de elementos semânticos que não foram precipitados.
} 
eurocêntrico foram fundantes para a constituição do marxismo na América Latina, tendo apresentado grandes desafios às primeiras gerações de marxistas latino-americanos.

\section{Referências Bibliográficas}

AMIN, S. El eurocentrismo (1989). Crítica de una ideología. Ciudad de México: Siglo Veintiuno Editores.

ANDERSON, K.B (2010). Marx at the margins. On nationalism, ethnicity and non-western societies. Chicago: University of Chicago Press.

BAGU, S (1949). Economía de la sociedad colonial. Ensayo de historia comparada de America Latina. Buenos Aires: El Ateneo Editorial.

CARONE, E (1986). O marxismo no Brasil (das origens a 1964). Rio de Janeiro: Dois Pontos.

CASANOVA, P.G. (1988). Sobre el marxismo en América Latina. Dialéctica. Revista de la Escuela de Filosofia y Letras de la Universidad Autônoma de Puebla, Puebla, n. 20, dez, p. 7-17.

(2006). Colonialismo interno (uma redefinição). In: BORON, A., AMADEO, J., GONZÁLEZ, S. (Org.). A teoria marxista hoje. Problemas e perspectivas. Buenos Aires; São Paulo: CLACSO; Expressão Popular. (Coleção Campus Virtual).

CASTRO, Juan E. (2010). ¿Fue José Carlos Mariátegui racista? A contra corriente. Una revista de historia social y literatura de América Latina, n. 2, v. 7, winter, p. 80-91 [Disponível em: www.ncsu.edu/project/acontracorriente. Acesso em: 25/02/2017]

CHAKRABARTY, D (2000). Provincializing Europe. Postcolonial thought and historical difference. Princeton: Princeton University Press.

CONNELL, R (2007). Southern theory. The global dynamics of knowledge in social Science. Cambridge: Polity Press.

ESCORSIM, L. (2006). Mariátegui. Vida e obra. São Paulo: Expressão Popular.

FORTE, V.L. (2016). Dilemas no marxismo do Sul: As tensões eurocêntricas na interpretação do Brasil de Caio Prado Jr. 2016. 248f. Tese (Doutorado em Sociologia) - Departamento de Ciências Sociais, Universidade Federal de Pernambuco, Recife.

GROSFOGUEL, R. (2013). Desenvolvimentismo, modernidade e teoria da dependência na América Latina. Realis, n.2,v.3, jul-dez, p. 26-55 [Disponível em: http://www.nucleodecidadania.org/revista/index.php/realis/article/view/87. Acesso em: 19/01/2015].

JAMES, C.L.R. (2010[1938]). Os jacobinos negros. Toussaint L'Ouverture e a revolução de São Domingos. São Paulo: Boitempo.

LANDER, E. Saberes coloniais e eurocêntricos. (2000). In: (org.). $A$ colonialidade do saber: eurocentrismo e ciências sociais. Perspectivas latinoamericanas. Buenos Aires: CLACSO. (Colección Sur Sur). 
LINDNER, K. (2010). Marx's eurocentrism. Postcolonial studies and Marx scholarship. Radical Philosophy, pp.27-41.

LÖWY, M. (2013). Introdução - dialética revolucionária contra a ideologia burguesa do progresso. In: MARX, K., ENGELS, F. Lutas de classes na Rússia. São Paulo: Boitempo.

(2012). Introdução. In: LÖWY, M. O marxismo na América Latina. Uma antologia de 1909 aos dias atuais. São Paulo: Fundação Perseu Abramo.

(1999). Marxismo e romantismo em Mariátegui. Teoria e Debate, ed. 41, mai. [Disponível em: http://www.teoriaedebate.org.br/materias/politica/marxismo-eromantismo-em-mariategui?page=full. Acesso em 22 de março de 2017].

MANTEGA, G. (1984). A Economia Política Brasileira. São Paulo: Vozes.

MARIÁTEGUI, J. C. (2010[1928]) Sete ensaios de interpretação da realidade peruana. São Paulo: Expressão Popular.

(2012[1928]). O socialismo indo-americano. In: LÖWY, M. O marxismo na América Latina. Uma antologia de 1909 aos dias atuais. São Paulo: Fundação Perseu Abramo.

MARIÁTEGUI, J. C., PESCE, H. (2010[1929]) El problema de las razas em la América Latina. In: MARIÁTEGUI, J. C. Ideología y política y otros escritos. Caracas: Findación Editorial El perro y la rana.

MARX, K. (2008c[1867]). A chamada acumulação primitiva. In: O capital - crítica da economia política. Rio de Janeiro: Civilização Brasileira. Livro I, Tomo II.

MARX, K., ENGELS, F. (2013[1882]). Prefácio à edição russa do manifesto do partido comunista. In: . Lutas de classes na Rússia. São Paulo: Boitempo.

PONS, S. (2014). A revolução global. História do comunismo internacional. 1917-1991. Rio de Janeiro: Contraponto.

QUIJANO, A. (2010). Colonialidade do poder e classificação social. In: SANTOS, B.S., MENESES, M.P. (Org.). Epistemologias do sul. São Paulo: Cortez, 2010.

RICUPERO, B. (2000). Caio Prado Jr. e a nacionalização do marxismo no Brasil. São Paulo: Perspectiva.

TIBLE, J. (2009). José Carlos Mariátegui: Marx e a América Indígena. Cadernos Cemarx, n ${ }^{\circ}$ 6, pp. 97-114.

WALLERSTEIN, I. (2007). O universalismo europeu: a retórica do poder. São Paulo: Boitempo.

WILLIAMS, R. (1979). Marxismo e literatura. Rio de Janeiro: Zahar.

ZASULITCH, V.I. (2013). Carta a Karl Marx, 16 fev. 1881. In: MARX, K., ENGELS, F. Lutas de classes na Rússia. São Paulo: Boitempo.

Recebido em: 24/04/2017 Aceito em: 20/07/2017. 